\title{
Somatostatin administration prior to ERCP is effective in reducing the risk of post-ERCP pancreatitis in high-risk patients
}

\author{
LI-NA ZHAO, TAO YU, CHU-QIANG LI, YU LAI and QI-KUI CHEN \\ Department of Gastroenterology, Sun Yat-Sen Memorial Hospital, Sun Yat-Sen University, \\ Guangzhou, Guangdong 510120, P.R. China
}

Received December 25, 2013; Accepted April 29, 2014

DOI: $10.3892 /$ etm.2014.1733

\begin{abstract}
Somatostatin has been extensively studied for the prophylaxis of pancreatitis following endoscopic retrograde cholangiopancreatography (ERCP). However, the results remain controversial. The present retrospective cohort study aimed to investigate the efficacy of pre- and post-ERCP somatostatin administration in the prevention of post-ERCP pancreatitis (PEP). All ERCP procedures performed at one hospital between January 2009 and December 2012 were reviewed. They were divided into three groups based on somatostatin administration: pre-ERCP som group (somatostatin administration: $0.25 \mathrm{mg} / \mathrm{h}$ for $24 \mathrm{~h}$, starting $1 \mathrm{~h}$ prior to ERCP), post-ERCP som group (somatostatin administration: $0.25 \mathrm{mg} / \mathrm{h}$ for $24 \mathrm{~h}$, starting immediately following ERCP), and control group (no somatostatin administration). Out of a total of 304 cases, 81 received pre-ERCP somatostatin; 126 received post-ERCP somatostatin and 97 were not administered somatostatin. Pre-ERCP somatostatin was effective in reducing the incidence of PEP compared with that in the control group (4.9 vs. $16.5 \%$; $\mathrm{P}=0.017$ ). This benefit was significant in high-risk patients ( 8.9 vs. $26.0 \%$; $\mathrm{P}=0.035)$, but not in low-risk patients ( 0 vs. $6.4 \%$; $\mathrm{P}=0.254$ ). Post-ERCP somatostatin was not effective in preventing PEP in high- or low-risk patients. In conclusion, pre-ERCP somatostatin may be effective in reducing the risk of PEP in high-risk patients, but not in low-risk patients. Post-ERCP somatostatin did not reveal a benefit in high- or low-risk patients. However, large randomized controlled trials are required to further confirm these findings.
\end{abstract}

Correspondence to: Dr Tao Yu, Department of Gastroenterology, Sun Yat-Sen Memorial Hospital, Sun Yat-Sen University, 107 Yan Jiang Xi Road, Guangzhou, Guangdong 510120, P.R. China E-mail: yutao2014@126.com

Key words: post-endoscopic retrograde cholangiopancreatography pancreatitis, somatostatin, retrospective study, prevention

\section{Introduction}

Endoscopic retrograde cholangiopancreatography (ERCP) is a widely available and routine procedure for treating a wide variety of pancreaticobiliary diseases. Due to its advantage of being a minimally invasive treatment, it is generally accepted as a valuable and promising therapeutic modality, especially in choledocholithiasis (1). However, a high frequency of complications is associated with the ERCP procedure. Post-ERCP pancreatitis (PEP) is the most common complication, with an incidence rate ranging from 1 to $15.1 \%$ of cases, rising to $30 \%$ in high-risk patients (2).

Numerous mechanisms have been proposed for the development of PEP (3). A common mechanism involves an initial pancreatic injury that leads to the premature activation of proteolytic enzymes. This initiates an inflammatory cascade that results in local and systemic effects. Two factors may lead to the initial pancreatic injury. One is the obstruction of pancreatic outflow caused by mechanical-, chemical-, or electrocautery-related thermal injury and consequent edema during cannulation and instrumentation of the papilla. The other factor is the increased hydrostatic pressure resulting from pancreatic duct injection (3).

Numerous methods, including ERCP techniques and pharmacological agents, have been introduced in an attempt to prevent PEP. Among the ERCP techniques, pancreatic duct stenting has been recommended to reduce PEP in high-risk patients (4). However, the challenging placement technique and the necessity for follow-up evaluations to ensure passage or removal have limited its clinical application. Therefore, various drugs have been considered that could be used to prevent PEP. Among these, somatostatin was identified as one of the most promising drugs and has thus been extensively studied. However, the results remain controversial (5-13). In the European Society of Gastrointestinal Endoscopy (ESGE) guidelines, prophylactic somatostatin administration is not recommended for average-risk patients. However, the administration of somatostatin may be more effective in high-risk patients or when administered using specific dose schedules (4). Therefore, further investigation is required to uncover appropriate methods of using prophylactic somatostatin for PEP prevention. 
The present retrospective cohort study was conducted to investigate the efficacy of pre- and post-ERCP somatostatin administration in the prevention of PEP.

\section{Patients and methods}

Patients and grouping. All ERCP procedures between January 2009 and December 2012 at the Sun Yat-Sen Memorial Hospital (Guangzhou, China) were reviewed. Hospitalized patients who had undergone ERCP procedures were included in the current study. The exclusion criteria included: i) hyperamylasemia at the baseline blood test; ii) acute pancreatitis prior to ERCP; and iii) failed cannulation.

Based on the different methods of somatostatin administration used at the hospital to prevent PEP, the patients were classified into the pre-ERCP som group, receiving somatostatin $1 \mathrm{~h}$ prior to ERCP by continuous intravenous infusion $(0.25 \mathrm{mg} / \mathrm{h})$ for $24 \mathrm{~h}$; the post-ERCP som group, receiving somatostatin immediately following ERCP by continuous intravenous infusion $(0.25 \mathrm{mg} / \mathrm{h})$ for $24 \mathrm{~h}$; and the control group, not receiving somatostatin administration. The patient demographics, indications, interventions, method of somatostatin administration and complications were noted for further analysis. Informed consent was obtained from the patients or the patients' families. The present study was approved by the ethics committee of Sun Yat-Sen Memorial Hospital.

ERCP procedures. All patients were fasted for $12 \mathrm{~h}$ prior to and at least $12 \mathrm{~h}$ following surgery. Intravenous sedation with meperidine and midazolam was given during the procedure. One dose of intravenous prophylactic antibiotic (cefoperazone $1 \mathrm{~g}$ ) and proton pump inhibitor were given following the procedure. Selective cannulation of the common bile duct was attempted in all patients and pancreatic duct cannulation was attempted only if indicated. Sphincterotomy and therapeutic procedures including stone extraction (balloon, basket or mechanical lithotripsy) and bile duct stenting (plastic stent) were performed when indicated. All ERCP procedures carried out in the present study were performed by the same experienced endoscopist. A difficult cannulation was defined as $\geq 3$ cannulation attempts. Details of the endoscopic procedure were recorded by the endoscopist immediately following the procedure.

Post-ERCP monitoring. All patients remained in the hospital for $\geq 72 \mathrm{~h}$ following ERCP. Serum amylase levels were routinely measured prior to ERCP (baseline) and at 6 and $24 \mathrm{~h}$ following ERCP. Patients' symptoms, including abdominal pain and tenderness, were also documented during the $24 \mathrm{~h}$ following ERCP.

PEP and hyperamylasemia definitions. PEP was defined as new or worsened abdominal pain and tenderness persisting for $>24 \mathrm{~h}$ following ERCP, with an elevated serum amylase level $>3$ times the normal upper limit. Based on previous studies, the severity of pancreatitis was classified as mild when the length of hospital stay was $\leq 3$ nights, moderate when the hospital stay was 4-10 nights, and severe if $>10$ days of hospitalization, intensive care unit admission, or surgery were required for the pancreatitis (14). The length of hospital stay was the number of days from the date of ERCP surgery until the date of the resolution of abdominal pain and reduction of serum amylase levels to <2-fold higher than the normal upper limit. The second outcome, hyperamylasemia, was defined as an elevation in serum amylase levels to at $>2$-fold higher the upper normal limit at 6 or $24 \mathrm{~h}$ following ERCP.

High-and low-risk patient definitions. Following careful consideration and discussion of various previous studies $(4,15)$, patients who satisfied one of the following risk factors of PEP were defined as high-risk patients in the current study: i) suspected sphincter of Oddi dysfunction (SOD), defined as a pre-ERCP suspicion of a functional or structural abnormality of the sphincter of Oddi, independent of any manometric findings, considered to be the potential cause of recurrent abdominal pain or pancreatitis; ii) recent acute pancreatitis; iii) precut sphincterotomy; iv) difficult cannulation (cannulation attempted $\geq 3$ times); and v) pancreatic duct injection $(4,15)$. Patients with none of the above risk factors were defined as low-risk patients.

Statistical analysis. Variables were reported using means (with standard deviations) and simple proportions. Analysis was performed using analysis of variance (ANOVA) and the $\chi^{2}$ test (or Fisher's exact test when appropriate). If a two-tailed P-value was $<0.05$ among the three groups, then further analysis was carried out to compare pre- or post-ERCP groups with the control group. Multivariate (logistic regression) analysis was also carried out to further confirm the effect of somatostatin on preventing PEP and to analyze the risk factors of PEP at the hospital. The data was analyzed with SPSS software version 13.0 (SPSS, Inc., Chicago, IL, USA). A twotailed P-value $<0.05$ was considered to indicate a statistically significant results.

\section{Results}

Patient data. There was a total of 343 ERCP cases from January 2009 to December 2012 at the hospital. Of these, 39 were excluded from further analysis: 25 due to serum amylase levels being higher than the normal upper limit prior to ERCP, 4 due to acute pancreatitis prior to ERCP and 10 due to failed cannulation. In the 304 enrolled cases, 81 cases received somatostatin $1 \mathrm{~h}$ prior to ERCP (pre-ERCP som group), 126 cases received somatostatin administration immediately following ERCP (post-ERCP som group) and the remaining 97 cases with no somatostatin administration were the control group.

Table I shows patient characteristics, ERCP indications and procedures. Overall, biliary ductal stones were identified as an indication of ERCP in $71.4 \%$ of the patients. No statistically significant differences in mean age, gender, SOD and ERCP indications were identified among the three groups. Among the procedures, pancreatic duct stenting was performed on only $8.2 \%$ of cases $(11.1 \%$ in the pre-ERCP som group, $7.9 \%$ in the post-ERCP som group and $6.2 \%$ in the control group). The proportions of patients undergoing difficult cannulation, precut sphincterotomy, pancreatic duct injection, biliary sphincterotomy, stone extraction, drain insertion and pancreatic duct stenting procedures were similar among the three groups. 
Table I. Baseline characteristics among the three groups.

\begin{tabular}{|c|c|c|c|c|}
\hline Characteristic & $\begin{array}{l}\text { Pre-ERCP som } \\
\qquad(\mathrm{n}=81)\end{array}$ & $\begin{array}{l}\text { Post-ERCP som } \\
\qquad(n=126)\end{array}$ & Control $(\mathrm{n}=97)$ & P-value \\
\hline Age (years; mean \pm SD) & $59.31 \pm 14.61$ & $56.06 \pm 14.38$ & $56.23 \pm 15.94$ & 0.262 \\
\hline Gender (female/male) & $41 / 40$ & $58 / 68$ & $52 / 45$ & 0.519 \\
\hline \multicolumn{5}{|l|}{ Indications [n (\%)] } \\
\hline Biliary ductal stones & $59(72.8)$ & $92(73.0)$ & $66(68.0)$ & 0.684 \\
\hline Recent acute pancreatitis & $9(11.1)$ & $8(6.3)$ & $7(7.2)$ & 0.438 \\
\hline Malignancy & $5(6.2)$ & $12(9.5)$ & $11(11.3)$ & 0.503 \\
\hline Others & $8(9.9)$ & $14(11.1)$ & $13(13.4)$ & 0.764 \\
\hline $\mathrm{SOD}[\mathrm{n}(\%)]$ & $15(18.5)$ & $27(21.4)$ & $14(14.4)$ & 0.414 \\
\hline Difficult cannulation $^{\mathrm{a}}[\mathrm{n}(\%)]$ & $16(19.8)$ & $17(13.5)$ & $12(12.4)$ & 0.349 \\
\hline Precut sphincterotomy [n (\%)] & $14(17.3)$ & $12(9.5)$ & $11(11.3)$ & 0.221 \\
\hline Pancreatic duct injection [n (\%)] & $26(32.1)$ & $44(34.9)$ & $34(35.1)$ & 0.906 \\
\hline Biliary sphincterotomy [n (\%)] & $66(81.5)$ & $100(79.4)$ & $76(78.4)$ & 0.888 \\
\hline Stone extraction $[\mathrm{n}(\%)]$ & $59(72.8)$ & $91(72.2)$ & $65(67.0)$ & 0.635 \\
\hline Drain insertion $^{\mathrm{b}}[\mathrm{n}(\%)]$ & $10(12.3)$ & $18(14.3)$ & $21(21.6)$ & 0.206 \\
\hline Pancreatic duct stenting [n (\%)] & $9(11.1)$ & $10(7.9)$ & $6(6.2)$ & 0.501 \\
\hline
\end{tabular}

Table II. Clinical outcomes of patients in the three groups.

\begin{tabular}{|c|c|c|c|c|}
\hline Clinical outcome & Pre-ERCP som $[\mathrm{n}=81 ; \mathrm{n}(\%)]$ & Post-ERCP som $[\mathrm{n}=126 ; \mathrm{n}(\%)]$ & Control $[\mathrm{n}=97 ; \mathrm{n}(\%)]$ & P-value \\
\hline PEP & $4(4.9)$ & $19(15.1)$ & $16(16.5)$ & $0.032^{\mathrm{a}}$ \\
\hline Mild & 4 & 14 & 11 & \\
\hline Moderate & 0 & 5 & 5 & \\
\hline Severe & 0 & 0 & 0 & \\
\hline Hyperamylasemia & $24(29.6)$ & $38(30.2)$ & $20(20.6)$ & 0.231 \\
\hline
\end{tabular}

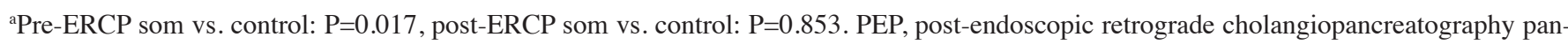
creatitis; pre-ERCP som, pre-endoscopic retrograde cholangiopancreatography somatostatin administration; post-ERCP som, post-endoscopic retrograde cholangiopancreatography somatostatin administration.

Incidences of PEP and hyperamylasemia. Among the 304 included ERCP cases, the overall incidences of PEP and hyperamylasemia were $12.8 \%$ (39/304) and 27.0\% (82/304), respectively. Most PEP was mild and mild PEP occurred in $9.5 \%$ of cases. Moderate PEP occurred in $3.3 \%$ of cases (none in the pre-ERCP som group, $4.0 \%$ in the post-ERCP som group and $5.2 \%$ in the control group). No severe PEP occurred. Statistical analysis revealed that the incidence of PEP in the pre-ERCP som group was significantly lower than that in control group (4.9 vs. $16.5 \%$; $\mathrm{P}=0.017$; Table II). However, somatostatin administration immediately following ERCP (post-ERCP som group), did not demonstrate the same benefit when compared with the control group (15.1 vs. $16.5 \%$; $\mathrm{P}=0.853$; Table II). Neither somatostatin administration in the pre-ERCP som group nor in the post-ERCP som group was able to reduce the incidence of hyperamylasemia compared with that in the control group $(\mathrm{P}=0.231$; Table II).

Incidences of PEP and hyperamylasemia in high-or low-risk patients. Of the 304 patients in this study, 160 were defined as high-risk and 144 as low-risk. Among high-risk patients, the overall incidences of PEP and hyperamylasemia were $21.3 \%$ (34/160) and 34.4\% (55/160), respectively. The incidence of PEP in high-risk patients in the pre-ERCP som group was significantly lower than in high-risk patients in the control group ( 8.9 vs. $26.0 \%$; $\mathrm{P}=0.035$; Table III); however, the difference was not significant between the post-ERCP som group and the control group (26.2 vs. $26.0 \%$; $\mathrm{P}=0.985$; Table III). In low-risk patients, the overall incidences of PEP and hyperamylasemia were $3.5 \%$ (5/144) and $25.7 \%$ (37/144), respectively. 
Table III. Clinical outcomes of high-risk patients in the three groups.

\begin{tabular}{|c|c|c|c|c|}
\hline Clinical outcome & Pre-ERCP som $[\mathrm{n}=45 ; \mathrm{n}(\%)]$ & Post-ERCP som $[\mathrm{n}=65 ; \mathrm{n}(\%)]$ & Control $[\mathrm{n}=50 ; \mathrm{n}(\%)]$ & P-value \\
\hline PEP & $4(8.9)$ & $17(26.2)$ & $13(26.0)$ & $0.045^{\mathrm{a}}$ \\
\hline Hyperamylasemia & $18(40.0)$ & $25(38.5)$ & $12(24.0)$ & 0.168 \\
\hline
\end{tabular}

aPre-ERCP som vs. control: $\mathrm{P}=0.035$; post-ERCP som vs. control: $\mathrm{P}=0.985$; PEP, post-endoscopic retrograde cholangiopancreatography pancreatitis; pre-ERCP som, pre-endoscopic retrograde cholangiopancreatography somatostatin administration; post-ERCP som, post-endoscopic retrograde cholangiopancreatography somatostatin administration.

Table IV. Clinical outcomes of low-risk patients in the three groups.

\begin{tabular}{|c|c|c|c|c|}
\hline Clinical outcome & Pre-ERCP som $[\mathrm{n}=36 ; \mathrm{n}(\%)]$ & Post-ERCP som $[\mathrm{n}=61 ; \mathrm{n}(\%)]$ & Control $[\mathrm{n}=47 ; \mathrm{n}(\%)]$ & P-value \\
\hline PEP & 0 & $2(3.3)$ & $3(6.4)$ & $0.371^{\mathrm{a}}$ \\
\hline Hyperamylasemia & $16(16.7)$ & $13(21.3)$ & $8(17)$ & 0.858 \\
\hline
\end{tabular}

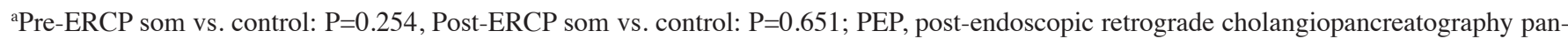
creatitis; pre-ERCP som, pre-endoscopic retrograde cholangiopancreatography somatostatin administration; post-ERCP som, post-endoscopic retrograde cholangiopancreatography somatostatin administration.

Table V. Factors associated with PEP in the multivariate analysis.

\begin{tabular}{|c|c|c|c|c|}
\hline Factor & PEP cases $(n=39)$ & Control $(n=265)$ & OR $(95 \% \mathrm{CI})$ & P-value \\
\hline Female & 19 & 151 & $0.85(0.38-1.90)$ & 0.688 \\
\hline Recent acute pancreatitis & 3 & 24 & $0.87(0.20-3.89)$ & 0.872 \\
\hline SOD & 15 & 56 & $4.70(1.86-11.89)$ & 0.001 \\
\hline Difficult cannulation $^{\mathrm{a}}$ & 14 & 45 & $5.76(1.75-19.02)$ & 0.004 \\
\hline Precut sphincterotomy & 9 & 37 & $0.45(0.12-1.75)$ & 0.249 \\
\hline Pancreatic duct injection & 26 & 104 & $4.37(1.93-9.93)$ & $<0.001$ \\
\hline Biliary sphincterotomy & 35 & 242 & $2.38(0.71-8.05)$ & 0.162 \\
\hline Pancreatic duct stenting & 3 & 25 & $0.15(0.03-0.78)$ & 0.024 \\
\hline Pre-ERCP som & 4 & 81 & $0.17(0.05-0.62)$ & 0.007 \\
\hline Post-ERCP som & 19 & 126 & $0.72(0.31-1.64)$ & 0.431 \\
\hline
\end{tabular}


tography pancreatitis; pre-ERCP som, pre-endoscopic retrograde cholangiopancreatography somatostatin administration; post-ERCP som, post-endoscopic retrograde cholangiopancreatography somatostatin administration; OR, odds ratio; CI, confidence interval.

The incidences of PEP among the pre-ERCP som group, post-ERCP som group and control group were similar $(0,3.3$, and $6.4 \%$, respectively; $\mathrm{P}=0.371$; Table IV). The incidence of hyperamylasemia in high-risk patients was not significantly different among the three groups $(\mathrm{P}=0.168$; Table III), nor was it significantly different in the low-risk patients $(\mathrm{P}=0.858$; Table IV).

Factors associated with PEP. To assess the independent role of the effect of somatostatin on PEP, logistic regression analysis for all the independent factors associated with PEP identified in previous studies (female gender, recent acute pancreatitis, SOD, difficult cannulation, precut sphincterotomy, pancreatic duct injection, biliary sphincterotomy, pancreatic duct stenting,
pre-ERCP somatostatin administration and post-ERCP somatostatin administration) was carried out (15). Pre-ERCP somatostatin administration was significantly associated with PEP reduction [odds ratio (OR) 0.17 ; $95 \%$ confidence interval (CI) 0.05-0.62; P=0.007; Table V]. Pancreatic duct stenting was also identified as a protective factor for PEP (OR 0.15; 95\% CI 0.03-0.78; $\mathrm{P}=0.024$; Table V). The factors SOD, difficult cannulation and pancreatic duct injection were identified as risk factors of PEP.

\section{Discussion}

ERCP is an effective and irreplaceable method for the diagnosis and treatment of pancreaticobiliary diseases. PEP is a 
common complication of ERCP with an incidence rate ranging from 1 to $15.1 \%$ of cases, which may increase to $30 \%$ in high-risk patients. Most PEP is relatively mild and the main consequence is prolonged hospital stay and increased healthcare expenditure. However, in rare cases $(\sim 0.3-0.6 \%)$ severe pancreatitis may be life threatening and have a devastating impact on the patient's quality of life (2). Consistent with previous studies, the results of the present study indicated that the overall frequency of PEP was $12.8 \%$ in all patients, $21.3 \%$ in high-risk patients and $3.5 \%$ in low-risk patients.

With many positive biological effects, including inhibition of exocrine pancreatic secretion, reduction of sphincter of Oddi contractions, modulation of the cytokine cascade and possible pancreatic acinar cytoprotection, somatostatin was believed to be one of the most promising drugs that could be used to reduce the risk of PEP (16-18). A meta-analysis of 10 randomized controlled trials (RCTs) concluded that somatostatin was able to reduce the risk of PEP (RR 0.52; 95\% CI 0.30-0.90), especially in cases of pancreatic duct injection, biliary sphincterotomy, high dose infusion over $12 \mathrm{~h}$, and bolus injection (19). However, in the ESGE guidelines, a meta-analysis of another 10 high-quality trials indicated that somatostatin administration did not result in a reduction of PEP (OR 0.57; 95\% CI $0.32-1.03)$. It further stated, however, that when the baseline incidence of PEP among the control group was $>10 \%$, a benefit to somatostatin administration was observed, and an infusion of somatostatin for $>12 \mathrm{~h}$ may improve its efficacy (4). In the current study, somatostatin administered $1 \mathrm{~h}$ prior to ERCP by continuous intravenous infusion $(0.25 \mathrm{mg} / \mathrm{h})$ for $24 \mathrm{~h}$ reduced the incidence of PEP (Table II). Further subgroup analysis indicated that this benefit was significant in high-risk patients but not in low-risk patients (Tables III and IV). Multivariate analysis also confirmed that pre-ERCP somatostatin was effective in reducing PEP (OR 0.17; 95\% CI 0.05-0.62; $\mathrm{P}=0.007$; Table V). These data suggest that pre-ERCP somatostatin administration may be effective in reducing the risk of PEP in high-risk cases.

In the majority of previous studies, somatostatin infusion was performed $30 \mathrm{~min}$ or $1 \mathrm{~h}$ prior to ERCP. The administration of somatostatin at these times makes it difficult to predict the risk factors associated with the procedure, including precut sphincterotomy, difficult cannulation, pancreatic duct injection and pancreatic sphincterotomy. As it is difficult to evaluate all the risk factors when somatostatin is administered exclusively as a prophylactic treatment prior to ERCP in high-risk cases, post-ERCP somatostatin was also studied. A RCT of 270 cases carried out by Poon et al revealed that the incidence of PEP was significantly lower in the group with somatostatin administration immediately following diagnostic ERCP but prior to therapeutic ERCP, when compared with that in the placebo group (4.4 vs. 13.3\%; P=0.01) (11). Another RCT carried out by Wang et al suggested that somatostatin administration $1 \mathrm{~h}$ following ERCP was effective in preventing hyperamylasemia in ERCP cases, but not in reducing PEP (20). The results of the present study suggest that somatostatin administration immediately following ERCP is an ineffective method of reducing PEP and hyperamylasemia, even in high-risk patients. A possible reason for this may be that the development of PEP is a process in which the inflammatory cascade reaction is initiated by pancreatic injury during ERCP. Thus, avoiding initial pancreatic injury is pivotal to preventing PEP. However, post-ERCP somatostatin administration is not able to reduce the initial pancreatic injury during the ERCP procedure. Therefore, earlier somatostatin administration is pivotal to reducing PEP and somatostatin administration prior to ERCP may be inevitable. However, this requires further investigation.

According to numerous prospective studies, the risk factors of PEP include patient-related risk factors (young age, female gender, recent acute pancreatitis and SOD) and procedure risk factors (precut sphincterotomy, difficult cannulation, pancreatic duct injection, and pancreatic sphincterotomy) (4). The present study also analyzed the risk factors of PEP using multivariate analysis. Consistent with previous studies, SOD, difficult cannulation and pancreatic duct injection were identified to be independent risk factors of PEP (Table V). However, certain known risk factors (gender, recent acute pancreatitis, and precut sphincterotomy) were not identified as risk factors of PEP in the current study. The major indicators of ERCP in the present study were biliary ductal stones. A study by Testoni et al demonstrated that in patients undergoing ERCP for biliary ductal stones, precut sphincterotomy did not appear to be an independent risk factor for PEP (21). Nevertheless, larger prospective studies are required to confirm these results.

Although the present study revealed that pre-ERCP somatostatin administration was an effective method of reducing the risk of PEP whereas post-ERCP somatostatin administration was not, the results have limitations. Firstly, the data collection was retrospective. Although the primary factors associated with PEP were accurately collected, potential bias was inevitable. Secondly, all the data was collected from medical records which may have contained inaccurate information. However, since the method of somatostatin administration was a pivotal factor for its efficacy in preventing PEP, the current study revealed that somatostatin administration $1 \mathrm{~h}$ prior to ERCP of $0.25 \mathrm{mg} / \mathrm{h}$ for $24 \mathrm{~h}$ was effective in reducing PEP in high-risk patients, but not in lowrisk patients.

In conclusion, somatostatin administration prior to ERCP may be effective in reducing the risk of PEP in high-risk patients, but not in low-risk patients. Somatostatin administration immediately following ERCP did not demonstrate this benefit in either high- or low-risk patients. However, large RCTs are required in order to confirm these results.

\section{Acknowledgements}

This study was funded by the National Natural Science Foundation of China (No. 81000152) and the Youthful Teacher Foster Plan of Sun Yat-Sen University (No. 09ykpy10).

\section{References}

1. Cohen S, Bacon BR, Berlin JA, et al: National Institutes of Health State-of-the-Science Conference Statement: ERCP for diagnosis and therapy, January 14-16. Gastrointest Endosc 56: 803-809, 2002.

2. Masci E, Mariani A, Curioni S and Testoni PA: Risk factors for pancreatitis following endoscopic retrograde cholangiopancreatography: a meta-analysis. Endoscopy 35: 830-834, 2003.

3. Donnellan F and Byrne MF: Prevention of post-ERCP pancreatitis. Gastroenterol Res Pract 2012: 796751, 2012. 
4. Dumonceau JM, Andriulli A, Deviere J, Mariani A, Rigaux J, Baron TH, Testoni PA; European Society of Gastrointestinal Endoscopy: European Society of Gastrointestinal Endoscopy (ESGE) Guideline: prophylaxis of post-ERCP pancreatitis. Endoscopy 42: 503-515, 2010.

5. Lee KT, Lee DH and Yoo BM: The prophylactic effect of somatostatin on post-therapeutic endoscopic retrograde cholangiopancreatography pancreatitis: a randomized, multicenter controlled trial. Pancreas 37: 445-448, 2008.

6. Andriulli A, Clemente R, Solmi L, et al: Gabexate or somatostatin administration before ERCP in patients at high-risk for post-ERCP pancreatitis: a multicenter, placebo-controlled, randomized clinical trial. Gastrointest Endosc 56: 488-495, 2002.

7. Andriulli A, Solmi L, Loperfido S, et al: Prophylaxis of ERCPrelated pancreatitis: a randomized, controlled trial of somatostatin and gabexate mesylate. Clin Gastroenterol Hepatol 2: 713-718, 2004.

8. Arvanitidis D, Anagnostopoulos GK, Giannopoulos D, et al: Can somatostatin prevent post-ERCP pancreatitis? Results of a randomized controlled trial. J Gastroenterol Hepatol 19: 278-282, 2004

9. Bordas JM, Toledo-Pimentel V, Llach J, Elena M, Mondelo F, Ginès $\mathrm{A}$ and Terés $\mathrm{J}$ : Effects of bolus somatostatin in preventing pancreatitis after endoscopic pancreatography: results of a randomized study. Gastrointest Endosc 47: 230-234, 1998.

10. Persson B, Slezak P, Efendic S and Häggmark A: Can somatostatin prevent injection pancreatitis after ERCP? Hepatogastroenterology 39: 259-261, 1992.

11. Poon RT, Yeung C, Liu CL, et al: Intravenous bolus somatostatin after diagnostic cholangiopancreatography reduces the incidence of pancreatitis associated with therapeutic endoscopic retrograde cholangiopancreatography procedures: a randomized controlled trial. Gut 52: 1768-1773, 2003.
12. Poon RT, Yeung C, Lo CM, Yuen WK, Liu CL and Fan ST: Prophylactic effect of somatostatin on post-ERCP pancreatitis: a randomized controlled trial. Gastrointest Endosc 49: 593-598, 1999.

13. Guelrud M, Mendoza S, Viera L and Gelrud D: Somatostatin prevents acute pancreatitis after pancreatic duct sphincter hydrostatic balloon dilation in patients with idiopathic recurrent pancreatitis. Gastrointest Endosc 37: 44-47, 1991.

14. Cotton PB, Lehman G, Vennes J, et al: Endoscopic sphincterotomy complications and their management: an attempt at consensus. Gastrointest Endosc 37: 383-393, 1991.

15. Cooper ST and Slivka A: Incidence, risk factors, and prevention of post-ERCP pancreatitis. Gastroenterol Clin North Am 36: 259-276, 2007

16. Gullo L, Priori P, Scarpignato C, Baldoni F, Mattioli G and Barbara L: Effect of somatostatin 14 on pure human pancreatic secretion. Dig Dis Sci 32: 1065-1070, 1987.

17. Karalis K, Mastorakos G, Chrousos GP and Tolis G: Somatostatin analogues suppress the inflammatory reaction in vivo. J Clin Invest 93: 2000-2006, 1994.

18. Lai KH, Lo GH, Cheng JS, et al: Effect of somatostatin on the sphincter of Oddi in patients with acute non-biliary pancreatitis. Gut 49: 843-846, 2001.

19. Omata F, Deshpande G, Tokuda Y, et al: Meta-analysis: somatostatin or its long-acting analogue, octreotide, for prophylaxis against post-ERCP pancreatitis. J Gastroenterol 45: 885-895, 2010.

20. Wang Z, Li W and Wu L: Could somatostatin prevent post-ERCP pancreatitis or hyperamylasemia? A randomized, double blind, controlled preliminary clinical trial. Gastrointest Endosc 71: AB299, 2010.

21. Testoni PA, Giussani A, Vailati C, Testoni S, Di Leo M and Mariani A: Precut sphincterotomy, repeated cannulation and post-ERCP pancreatitis in patients with bile duct stone disease. Dig Liver Dis 43: 792-796, 2011. 